\title{
Prenatal antibiotic exposure and risk of attention-deficit/hyperactivity disorder: a population-based cohort study
}

\author{
Amani F. Hamad PhD, Silvia Alessi-Severini PhD, Salaheddin Mahmud MD PhD, Marni Brownell PhD, \\ I fan Kuo PharmD MSc
}

Cite as: CMAJ 2020 May 19;192:E527-35. doi: 10.1503/cmaj.190883

\begin{abstract}
BACKGROUND: Abnormal microbiota composition induced by prenatal exposure to antibiotics has been proposed as a potential contributor to the development of attention-deficit/hyperactivity disorder (ADHD). We examined the association between prenatal antibiotic exposure and risk of ADHD.
\end{abstract}

METHODS: We conducted a populationbased retrospective cohort study of children born in Manitoba, Canada, between 1998 and 2017 and their mothers. We defined exposure as the mother having filled 1 or more antibiotic prescriptions during pregnancy. The outcome was diagnosis of ADHD in the offspring, as identified in administrative databases. We estimated hazard ratios (HRs) using Cox proportional hazards regression in the overall cohort, in a separate cohort matched on high-dimensional propensity scores and in a sibling cohort.

RESULTS: In the overall cohort, consisting of 187605 children, prenatal antibiotic dispensation was associated with increased risk of ADHD (HR 1.22, 95\% confidence interval [CI] 1.18-1.26). Similar results were observed in the matched cohort of 129674 children (HR 1.20, 95\% Cl 1.15-1.24) but not in the sibling cohort (HR 1.06, 95\% Cl 0.99-1.13). Two negative-control analyses indicated a positive association with ADHD despite the lack of a reasonable biological mechanism, which suggested that the observed association between prenatal antibiotic dispensation and risk of ADHD was likely due to confounding.

INTERPRETATION: In our study, prenatal antibiotic exposure was not associated with increased risk of ADHD in children. Although the risk was higher in the overall and matched cohorts, it was likely overestimated because of unmeasured confounding. Future studies are warranted to examine other factors affecting microbiota composition in association with risk of ADHD.
A ttention-deficit/hyperactivity disorder (ADHD) is a neurodevelopmental disorder ${ }^{1,2}$ that is associated with many long-term adverse health and social outcomes, such as comorbid depression and anxiety, drug abuse, motor vehicle collisions and work absenteeism. ${ }^{3-6}$ Worldwide, the estimated prevalence of ADHD among children and adolescents is 5.3\% to $7.1 \%{ }^{7,8}$ Although no national data on ADHD prevalence are available for Canada, prevalence was 5.5\% among children aged 6 to 19 years between 2005 and 2009 in the province of Manitoba, and increased to $6.8 \%$ between 2009 and $2013 .{ }^{9}$ Genetic factors are important contributors to the development of ADHD, with variation in the trait being attributable to genetic differences in about $74 \%$ of cases. ${ }^{10,11}$ In addition, environmental factors such as maternal age at delivery, prenatal smoking and illicit drug use, maternal depression and prenatal exposure to antidepressant medications have also been suggested to be associated with risk of ADHD. ${ }^{12-16}$
Recent studies have shown that people with ADHD have abnormal microbiota composition. ${ }^{17,18}$ Dysbiosis, or the perturbation of microbiota composition, in the maternal gut may disrupt the fetal gut-brain axis in utero and potentially plays a role in the occurrence of neurodevelopmental disorders. ${ }^{19-27}$ Given recent evidence of microbiota transfer in utero and antibioticinduced fetal dysbiosis, ${ }^{28-31}$ we aimed to examine the association between prenatal antibiotic exposure and the risk of ADHD.

\section{Methods}

\section{Design, study setting and participants}

We conducted a population-based retrospective cohort study of children born between 1998 and 2017 in the province of Manitoba, Canada. We extracted data from the Manitoba Population Research Data Repository, a collection of de-identified 
administrative, registry, survey and other types of data housed at the Manitoba Centre for Health Policy.

We included all children registered in the Manitoba Health Insurance Registry who were born between Apr. 1, 1998, and Mar. 31,2017 . For each child, a minimum of 4 years of valid Manitoba health registration was required to meet the minimum age for a valid ADHD diagnosis, as recommended by the American Academy of Pediatrics. ${ }^{32}$ For each mother, a minimum of 2 years of health registration before the child's birthdate was required to capture maternal baseline characteristics, such as health care use before conception and the diagnosis of mood and anxiety disorders. We followed the children from birthdate (index date) to the earliest date of diagnosis of ADHD, migration out of the province, reaching age 18 years, death or end of the study period.

We conducted the analyses for 3 cohorts. The first cohort comprised all children who met the inclusion criteria. The second cohort consisted of members of the overall cohort who were matched on high-dimensional propensity scores. To identify this cohort, we scanned all available administrative databases for predictors of the exposure and then estimated the propensity score, which is the probability of being exposed, given the values of all covariables. ${ }^{33}$ High-dimensional propensity scores were later used to adjust for confounding by ensuring that the 2 groups were balanced in their characteristics. ${ }^{34}$ The third cohort consisted of children who had at least 1 maternal sibling who did not have prenatal exposure to antibiotics.

Other data sources used in the study are described in Appendix 1 (available at www.cmaj.ca/lookup/suppl/doi:10.1503/ cmaj.190883/-/DC1).

\section{Exposure}

We defined prenatal exposure to antibiotics as the mother having filled 1 or more outpatient antibiotic prescriptions during her pregnancy. We determined birthdate and gestational age from birth records and used these dates to estimate the date of conception. In secondary analyses, we examined the association between prenatal antibiotic exposure and risk of ADHD according to pregnancy trimester, number of antibiotic courses, cumulative duration of use and antibiotic class (Appendix 2, available at www.cmaj.ca/lookup/suppl/doi:10.1503/cmaj.190883/-/DC1).

\section{Outcome}

The main outcome measure was a diagnosis of ADHD with hyperactivity after age 4 . We used the coding systems in the clinical modification of the International Classification of Diseases, 9th Revision (ICD-9-CM), and the International Statistical Classification of Diseases and Related Health Problems, 10th Revision (ICD-10), to identify the diagnosis of ADHD in physician outpatient claims and hospitalization records, respectively. We used the Anatomical Therapeutic Chemical drug classification system to identify drugs for treating ADHD in prescriptionmedication dispensations. We used a standard identification algorithm, which defined diagnosis of ADHD as 1 or more hospital admissions with a diagnosis of hyperkinetic syndrome (ICD9-CM code 314 or ICD-10 code F90), 1 or more physician visits with a diagnosis of hyperkinetic syndrome (ICD-9-CM code 314), or 2 or more prescriptions for ADHD drugs (Anatomical Therapeutic Chemical code N06BA) within a single year without a diagnosis of conduct disorder (ICD-9-CM code 312 or ICD-10 codes F63, F91, F92), disturbance of emotions (ICD-9-CM code 313 or ICD-10 codes F93, F94) or cataplexy/narcolepsy (ICD-9-CM code 347 or ICD-10 code G47.4), to avoid misidentification of cases on the basis of drug dispensations. ${ }^{9,35-38}$

\section{Covariables}

We explored sociodemographic characteristics and other clinically important variables previously reported to be associated with risk of ADHD for inclusion in our analyses..$^{12,39,40}$ We adjusted models based on the overall cohort for sex, mother's age at delivery (categorized as $<30 \mathrm{yr}, 30-39 \mathrm{yr}$ and $\geq 40 \mathrm{yr}$ ), region of residence, receipt of income assistance, year of the child's birth, birth order, mother's medical conditions, prenatal exposure to antidepressants and frequency of physician visits in the year before conception. We included prenatal smoking, alcohol use and drug use in a sensitivity analysis of a subset of the cohort for whom these variables were available. We adjusted models based on the sibling cohort for sex, mother's age at delivery, birth order, year of the child's birth and prenatal exposure to antidepressants.

We estimated high-dimensional propensity scores using 5 dimensions and used these scores to match children with and without exposure to antibiotics. We identified mothers' hospital medical diagnoses and procedures (2 dimensions), outpatient medical diagnoses and tariff codes (2 dimensions), and drug dispensations ( 1 dimension) during the year before the estimated conception date. We then identified the 200 most prevalent variables in each dimension and ranked them according to their frequency as once, sporadic or frequent. We selected 500 variables for inclusion in estimation of high-dimensional propensity scores, in addition to sex, region of residence, Socio-Economic Factor Index (a measure of socioeconomic status derived from census data and based on area of residence), ${ }^{41}$ receipt of income assistance, mother's age at delivery, birth order, season of birth, year of the child's birth and number of physician visits by the mother in the year before conception. We included in the regression models variables that were not sufficiently balanced between the exposure groups.

\section{Statistical analysis}

In both the overall and the sibling cohorts, we used multivariable Cox proportional hazards regression models to compare risk of ADHD between children with and without prenatal exposure to antibiotics. In the sibling cohort, we stratified the models by sibling pairs to account for correlation among siblings.

We used multivariable Cox proportional hazards regression models, stratified by matched pair, to compare risk of ADHD in the cohort matched on high-dimensional propensity scores. Children with exposure to antibiotics prenatally were matched to those without exposure in a 1-to-1 nearest-neighbour greedy match on sex, birthdate (within $365 \mathrm{~d}$ ) and high-dimensional propensity scores within a caliper of 0.05 . We examined balance across the 2 exposure groups by calculating the standardized 
differences for sociodemographic characteristics, birth characteristics and relevant maternal medical conditions at baseline (Appendix 3, available at www.cmaj.ca/lookup/suppl/ doi:10.1503/cmaj.190883/-/DC1).

In the secondary analyses, we used indicator variables for each of the categories, with mutual adjustment for these variables in the models. We tested the assumption of proportional hazards by examining the correlation between various forms of follow-up time and Schoenfeld residuals of the independent variables. We also performed several sensitivity analyses, including use of stricter identification algorithms and cohort restrictions (see Appendix 4, available at www.cmaj.ca/lookup/suppl/ doi:10.1503/cmaj.190883/-/DC1). In addition, we conducted 2 negative-control analyses, examining the effect of maternal antibiotic exposure in the year before conception and the year after birth on risk of ADHD in the children. We performed these analyses to assess the risk of bias in the main analysis.

We used SAS 9.4 statistical software (SAS Institute) for all data analyses.

\section{Ethics approval}

The study was approved by the University of Manitoba Health Research Ethics Board (project no. H2016:244) and the Health Information Privacy Committee of Manitoba Health, Seniors and Active Living (HIPC no. 2016/2017-11).

\section{Results}

\section{Study population}

Of 289449 births in Manitoba during the study period, 187605 children met the inclusion criteria (Figure 1). In total, 70554 (37.6\%) children were exposed to antibiotics prenatally (Table 1 ). Among these children, $62.7 \%$ were exposed to only 1 antibiotic course, $73.9 \%$ were exposed to antibiotics for a cumulative duration of up to 2 weeks, and $50.7 \%$ were exposed to a penicillin antibiotic (Appendix 5, available at www.cmaj.ca/lookup/suppl/ doi:10.1503/cmaj.190883/-/DC1). The children were followed for a total of 1990452 person-years, with a median of 10.1 (interquartile range [IQR] 6.8-14.3) person-years (Table 2).

During follow-up, 16290 (8.7\%) of the children received a diagnosis of ADHD at a median age of 7.5 (IQR 6.0-9.5) years. The crude incidences for ADHD diagnosis were 10.3 cases per 1000 person-years among children with prenatal exposure to antibiotics and 6.9 cases per 1000 person-years among those without such exposure (Table 2; Appendix 6, available at www.cmaj.ca/ lookup/suppl/doi:10.1503/cmaj.190883/-/DC1).

In the second cohort, 129674 children were matched on high-dimensional propensity scores, sex and birthdate. The baseline characteristics were well balanced between the 2 exposure groups, with standardized differences of less than 0.1 for all of the variables examined, except maternal asthma (Table 1).

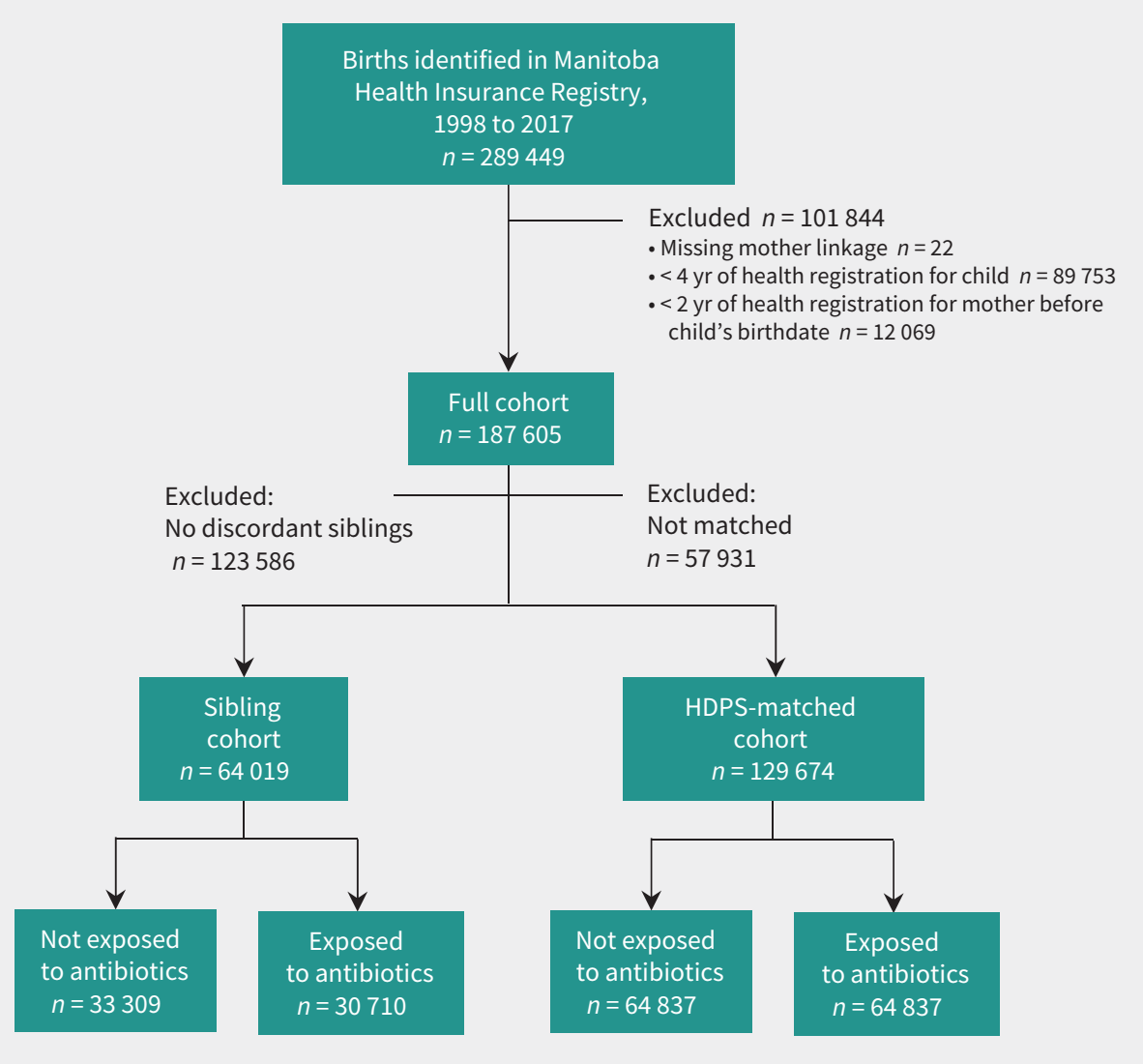

Figure 1: Derivation of the overall cohort, the cohort matched on high-dimensional propensity scores and the sibling cohort. 
Table 1: Baseline and birth characteristics of the overall cohort and the cohort matched on high-dimensional propensity scores (HDPS)*

\begin{tabular}{|c|c|c|c|c|c|c|}
\hline \multirow[b]{2}{*}{ Characteristic } & \multicolumn{3}{|c|}{$\begin{array}{l}\text { Overall cohort } \\
n=187605\end{array}$} & \multicolumn{3}{|c|}{$\begin{array}{c}\text { HDPS-matched cohort } \\
\qquad n=129674\end{array}$} \\
\hline & $\begin{array}{l}\text { Unexposed } \\
n=117051\end{array}$ & $\begin{array}{c}\text { Exposed } \\
n=70554\end{array}$ & $\begin{array}{l}\text { Standardized } \\
\text { difference }\end{array}$ & $\begin{array}{l}\text { Unexposed } \\
n=64837\end{array}$ & $\begin{array}{c}\text { Exposed } \\
n=64837\end{array}$ & $\begin{array}{l}\text { Standardized } \\
\text { difference }\end{array}$ \\
\hline Sex, male & $59894(51.2)$ & $36172(51.3)$ & 0.002 & 33358 (51.5) & $33358(51.5)$ & 0.000 \\
\hline Urban region of residence & $65305(55.8)$ & $36418(51.6)$ & 0.084 & $33417(51.5)$ & $33488(51.7)$ & 0.002 \\
\hline Socioeconomic status $\dagger$ & & & 0.174 & & & 0.066 \\
\hline High & $12873(11.0)$ & $5340(7.6)$ & & $5995(9.3)$ & $5223(8.1)$ & \\
\hline Middle & $44027(37.6)$ & $23105(32.8)$ & & $23084(35.6)$ & $22065(34.0)$ & \\
\hline Low middle & 35291 (30.2) & 23319 (33.1) & & $20448(31.5)$ & $21425(33.0)$ & \\
\hline Low & $24860(21.2)$ & $18790(26.6)$ & & $15310(23.6)$ & $16124(24.9)$ & \\
\hline Receiving income assistance $\ddagger$ & $18503(15.8)$ & $20652(29.3)$ & 0.326 & $15681(24.2)$ & $16717(25.8)$ & 0.037 \\
\hline Maternal age at delivery, mean \pm SD & $28.7 \pm 5.8$ & $27.6 \pm 5.9$ & 0.185 & $27.8 \pm 5.8$ & $27.7 \pm 5.9$ & 0.008 \\
\hline Breastfeeding initiation§ & $95919(82.3)$ & $54251(77.2)$ & 0.127 & $51865(80.4)$ & $50709(78.5)$ & 0.045 \\
\hline Preterm delivery & $8139(7.0)$ & $5578(7.9)$ & 0.036 & $4694(7.3)$ & $4962(7.7)$ & 0.016 \\
\hline Cesarean delivery & $23213(19.8)$ & $14654(20.8)$ & 0.023 & $12837(19.8)$ & $13571(20.9)$ & 0.028 \\
\hline First-born child & $45645(39.0)$ & $24946(35.4)$ & 0.075 & $24272(37.4)$ & $23731(36.6)$ & 0.017 \\
\hline Small for gestational age $\mathrm{e}^{\star \star}$ & $9046(7.7)$ & $5273(7.5)$ & 0.010 & $4943(7.6)$ & $4795(7.4)$ & 0.009 \\
\hline Birth complicationst† & $11743(10.0)$ & $7150(10.1)$ & 0.003 & $6356(9.8)$ & $6623(10.2)$ & 0.014 \\
\hline Prenatal smoking $\ddagger \ddagger$ & $12296(15.4)$ & $11801(25.3)$ & 0.247 & $8518(19.7)$ & $10131(23.4)$ & 0.089 \\
\hline Prenatal alcohol or drug use§§ & $8948(11.4)$ & $7117(15.5)$ & 0.121 & $5719(13.4)$ & $6270(14.7)$ & 0.037 \\
\hline \multicolumn{7}{|l|}{ Maternal medical conditions } \\
\hline Mood and anxiety disorders & $17082(14.6)$ & $16502(23.4)$ & 0.226 & $11930(18.4)$ & $13567(20.9)$ & 0.064 \\
\hline Asthma & $5557(4.8)$ & 8399 (11.9) & 0.261 & $4083(6.3)$ & $6854(10.8)$ & 0.154 \\
\hline Developmental disabilities & $1994(1.7)$ & $2029(2.9)$ & 0.078 & $1382(2.1)$ & $1689(2.6)$ & 0.031 \\
\hline \multicolumn{7}{|c|}{ 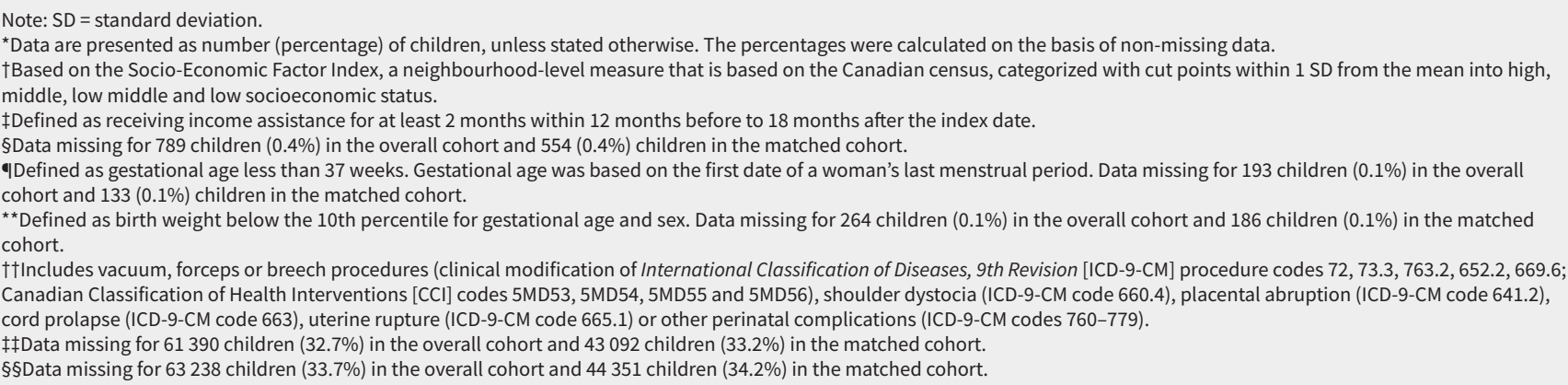 } \\
\hline
\end{tabular}

The children were followed for a total of 1374484 person-years, with a median of 10.0 (IQR 6.8-14.4) person-years. During follow-up, 12099 (9.3\%) of the children received a diagnosis of ADHD. The crude incidences for ADHD diagnosis were 9.6 cases per 1000 person-years among children with prenatal exposure to antibiotics and 8.0 cases per 1000 person-years among those without such exposure (Table 2; Appendix 6).

The sibling cohort consisted of 64019 children and 44491 exposure-discordant pairs. The baseline characteristics of this cohort are described in Appendix 7 (available at www.cmaj.ca/ lookup/suppl/doi:10.1503/cmaj.190883/-/DC1), and antibiotic exposure is described in Appendix 5. During total follow-up of 687350 person-years, $6025(9.4 \%)$ of the children received a diagnosis of ADHD (Table 3). The crude incidences for ADHD diagnosis were 9.5 cases per 1000 person-years among children with prenatal exposure to antibiotics and 8.1 cases per 1000 person-years in children among those without such exposure (Table 3; Appendix 6).

\section{Primary and secondary analyses}

In the overall cohort, prenatal antibiotic exposure was associated with an increased risk of ADHD (hazard ratio [HR] 1.22, 95\% confidence interval $[\mathrm{Cl}]$ 1.18-1.26) (Figure 2). The highest 
Table 2: Association between antibiotic exposure and risk of attention-deficit/hyperactivity disorder in the overall cohort and the cohort matched on HDPS

\begin{tabular}{|c|c|c|c|c|c|c|}
\hline \multirow[b]{2}{*}{ Variable } & \multicolumn{3}{|c|}{$\begin{array}{l}\text { Overall cohort } \\
n=187605\end{array}$} & \multicolumn{3}{|c|}{$\begin{array}{l}\text { HDPS-matched cohort } \\
\qquad n=129674\end{array}$} \\
\hline & $\begin{array}{l}\text { No. of } \\
\text { events }\end{array}$ & $\begin{array}{l}\text { Person- } \\
\text { years* }\end{array}$ & $\begin{array}{c}\text { HR† } \\
(95 \% \mathrm{CI})\end{array}$ & $\begin{array}{l}\text { No. of } \\
\text { events }\end{array}$ & $\begin{array}{l}\text { Person- } \\
\text { years* }\end{array}$ & $\begin{array}{c}\text { HR } \ddagger \\
(95 \% \mathrm{CI})\end{array}$ \\
\hline \multicolumn{7}{|l|}{ Main analysis } \\
\hline \multicolumn{7}{|l|}{ Prenatal antibiotic exposure } \\
\hline Unexposed & 8649 & 1247467 & 1.00 (Ref.) & 5500 & 690186 & 1.00 (Ref.) \\
\hline Exposed & 7641 & 742985 & $1.22(1.18-1.26)$ & 6599 & 684298 & $1.20(1.15-1.24)$ \\
\hline \multicolumn{7}{|l|}{ Secondary analyses } \\
\hline \multicolumn{7}{|l|}{ Exposure by trimester§₫ } \\
\hline None & 8649 & 1247467 & 1.00 (Ref.) & 5500 & 690186 & 1.00 (Ref.) \\
\hline First & 3722 & 333818 & $1.13(1.09-1.17)$ & 3094 & 298488 & $1.12(1.05-1.19)$ \\
\hline Second & 3919 & 352091 & $1.17(1.13-1.22)$ & 3270 & 317862 & $1.19(1.12-1.27)$ \\
\hline Third & 3256 & 314554 & $1.12(1.07-1.16)$ & 2752 & 286035 & $1.07(1.00-1.14)$ \\
\hline \multicolumn{7}{|l|}{ Antibiotic class $₫$} \\
\hline None & 8649 & 1247467 & 1.00 (Ref.) & 5500 & 690186 & 1.00 (Ref.) \\
\hline Penicillin & 5150 & 500082 & $1.15(1.12-1.19)$ & 4419 & 458112 & $1.12(1.06-1.17)$ \\
\hline Non-penicillin $\beta$-lactams & 1489 & 133529 & $1.18(1.12-1.25)$ & 1220 & 118134 & $1.14(1.04-1.25)$ \\
\hline Macrolides and related antibiotics & 1675 & 131987 & $1.17(1.11-1.24)$ & 1336 & 116915 & $1.30(1.18-1.42)$ \\
\hline Other & 2176 & 194694 & $1.09(1.04-1.14)$ & 1806 & 174912 & $1.08(1.00-1.17)$ \\
\hline \multicolumn{7}{|l|}{ No. of antibiotic courses } \\
\hline 0 & 8649 & 1247467 & 1.00 (Ref.) & 5500 & 690186 & 1.00 (Ref.) \\
\hline 1 & 4317 & 467362 & $1.16(1.12-1.20)$ & 3938 & 444343 & $1.18(1.13-1.24)$ \\
\hline 2 & 1898 & 168403 & $1.26(1.20-1.33)$ & 1623 & 153050 & $1.22(1.13-1.32)$ \\
\hline$\geq 3$ & 1426 & 107221 & $1.39(1.31-1.47)$ & 1038 & 86904 & $1.22(1.11-1.35)$ \\
\hline \multicolumn{7}{|l|}{ Cumulative antibiotic duration, $d$} \\
\hline 0 & 8649 & 1247467 & 1.00 (Ref.) & 5500 & 690186 & 1.00 (Ref.) \\
\hline $1-7$ & 2780 & 306543 & $1.16(1.11-1.21)$ & 2534 & 291069 & $1.16(1.10-1.24)$ \\
\hline $8-14$ & 2412 & 241468 & $1.20(1.14-1.25)$ & 2143 & 226189 & $1.19(1.11-1.27)$ \\
\hline$>14$ & 2449 & 194975 & $1.33(1.27-1.39)$ & 1922 & 167040 & $1.26(1.17-1.35)$ \\
\hline \multicolumn{7}{|c|}{$\begin{array}{l}\text { Note: } \mathrm{Cl}=\text { confidence interval, HDPS = high-dimensional propensity score, } \mathrm{HR}=\text { hazard ratio, Ref. = reference. } \\
\text { *Values for person-years were rounded to the nearest integer. } \\
\text { tAdjusted for sex, mother's age at delivery, region of residence, receipt of income assistance, year of child's birth, birth order, mother's medical conditions, prenatal exposure to } \\
\text { antidepressants and number of physician visits by the mother in the year before pregnancy. } \\
\text { tAdjusted for maternal diagnosis of asthma. } \\
\text { \$First trimester }=0-13 \text { weeks of pregnancy, second trimester }=14-27 \text { weeks, third trimester }=28 \text { weeks until date of birth. } \\
\text { IA child could be exposed to antibiotics during multiple trimesters and could be exposed to multiple antibiotic classes. }\end{array}$} \\
\hline
\end{tabular}

risk was observed for those whose mothers filled 3 or more courses of antibiotic (HR 1.39, 95\% Cl 1.31-1.47) or had a duration of antibiotic therapy longer than 2 weeks ( $\mathrm{HR} 1.33,95 \% \mathrm{Cl}$ 1.27-1.39) (Table 2). The association did not change significantly in the matched cohort (HR 1.20, 95\% Cl 1.15-1.24), where the highest risk was observed for those whose mothers filled 3 or more antibiotic courses (HR 1.22, 95\% Cl 1.11-1.35), had treatment duration longer than 2 weeks (HR 1.26, 95\% Cl 1.17-1.35) or had dispensation of a macrolide (HR $1.30,95 \% \mathrm{Cl}$ 1.18-1.42) (Table 2). In the sibling cohort, prenatal antibiotic dispensation was not associated with increased risk of ADHD
(HR 1.06, 95\% Cl 0.99-1.13). No significant variation in the risk was observed in the secondary analyses of the sibling cohort (Table 3).

\section{Sensitivity and negative-control analyses}

We found no major changes in the HRs in the planned sensitivity analyses (Figure 2); however, the risk increase was less apparent when children were censored at age 6 .

Dispensation of antibiotics to the mother in the year before conception and the year after childbirth was associated with increased risk of ADHD in the child (HR 1.18, 95\% Cl 1.15-1.22, 
Table 3: Association between antibiotic exposure and risk of attention-deficit/hyperactivity disorder in the sibling cohort $(n=64019)$

Type of analysis; HR (95\% Cl)

\begin{tabular}{|c|c|c|c|c|}
\hline Variable & No. of events & Person-years* & Unadjusted & Adjusted $\dagger$ \\
\hline \multicolumn{5}{|l|}{ Main analysis } \\
\hline \multicolumn{5}{|l|}{ Prenatal antibiotic exposure } \\
\hline Unexposed & 2913 & 360947 & 1.00 (Ref.) & 1.00 (Ref.) \\
\hline Exposed & 3112 & 326402 & $1.07(1.01-1.14)$ & $1.06(0.99-1.13)$ \\
\hline \multicolumn{5}{|l|}{ Secondary analyses } \\
\hline \multicolumn{5}{|l|}{ Exposure by trimester $\S$} \\
\hline None & 2913 & 360947 & 1.00 (Ref.) & 1.00 (Ref.) \\
\hline First & 1446 & 138371 & $1.02(0.94-1.11)$ & $1.03(0.94-1.13)$ \\
\hline Second & 1506 & 145603 & $1.13(1.04-1.23)$ & $1.10(1.00-1.20)$ \\
\hline Third & 1258 & 131952 & $1.02(0.93-1.11)$ & $1.02(0.93-1.12)$ \\
\hline \multicolumn{5}{|l|}{ Antibiotic class§ } \\
\hline None & 2913 & 360947 & 1.00 (Ref.) & 1.00 (Ref.) \\
\hline Penicillin & 2063 & 215600 & $1.01(0.94-1.09)$ & $1.03(0.95-1.11)$ \\
\hline Non-penicillin $\beta$-lactams & 582 & 55855 & $1.18(1.04-1.34)$ & $1.09(0.96-1.25)$ \\
\hline Macrolides and related antibiotics & 700 & 55595 & $1.12(0.99-1.26)$ & $1.07(0.95-1.21)$ \\
\hline Other & 784 & 77095 & $1.01(0.90-1.13)$ & $1.01(0.89-1.13)$ \\
\hline \multicolumn{5}{|l|}{ No. of antibiotic courses } \\
\hline 0 & 2913 & 360947 & 1.00 (Ref.) & 1.00 (Ref.) \\
\hline 1 & 1921 & 223769 & $1.05(0.98-1.13)$ & $1.04(0.96-1.12)$ \\
\hline 2 & 750 & 68775 & $1.10(0.98-1.28)$ & $1.11(0.99-1.25)$ \\
\hline$\geq 3$ & 441 & 33859 & $1.12(0.97-1.30)$ & $1.10(0.95-1.28)$ \\
\hline \multicolumn{5}{|l|}{ Cumulative antibiotic duration, $d$} \\
\hline 0 & 2913 & 360947 & 1.00 (Ref.) & 1.00 (Ref.) \\
\hline $1-7$ & 1233 & 146636 & $1.06(0.97-1.16)$ & $1.04(0.95-1.15)$ \\
\hline $8-14$ & 1039 & 110020 & $1.04(0.94-1.14)$ & $1.03(0.94-1.14)$ \\
\hline$>14$ & 840 & 69746 & $1.14(1.02-1.28)$ & $1.13(1.01-1.27)$ \\
\hline
\end{tabular}

Note: $\mathrm{Cl}$ = confidence interval, $\mathrm{HR}$ = hazard ratio, Ref. = reference

*Values for person-years were rounded to the nearest integer.

$\dagger$ Adjusted for sex, mother's age at delivery, birth order, year of birth and prenatal exposure to antidepressants.

†First trimester $=0-13$ weeks of pregnancy, second trimester $=14-27$ weeks, third trimester $=28$ weeks until date of birth.

$\S A$ child could be exposed to antibiotics during multiple trimesters and could be exposed to multiple antibiotic classes.

and HR 1.23, 95\% Cl 1.19-1.27, respectively) (Figure 2). Contrary to the analysis in the overall cohort, maternal exposure to antibiotics in the year before conception and the year after childbirth was not associated with increased risk of ADHD in the sibling cohort (HR 1.04, 95\% Cl 0.97-1.11, and $\mathrm{HR} 0.99,95 \% \mathrm{Cl}$ 0.92-1.06, respectively).

\section{Interpretation}

In our study, prenatal antibiotic exposure was not associated with increased risk of ADHD in children. Although we observed an increased risk with prenatal antibiotic exposure in the overall cohort and the matched cohort, we did not observe this association in the sibling cohort. The risk of ADHD was similar between the overall cohort and the matched cohort on highdimensional propensity scores, sex and birthdate, which suggests that matching did not add further control for confounding beyond adjustment for the covariables in the multivariable model. The increased risk of ADHD was no longer present in the sibling cohort analysis, which would be less susceptible to unmeasured confounding by genetics and other shared factors relative to the overall and matched cohorts. This observation can be explained by the important contribution of genetics in the development of ADHD, ${ }^{10,11}$ which is partially adjusted for in the sibling-controlled analysis.

Several sensitivity analyses confirmed that the risk estimates were not sensitive to changes in exposure, outcome or covariable definitions. An association was observed in both planned 


\section{Main analysis}

Prenatal antibiotic exposure

\section{Sensitivity analyses}

Stricter ADHD identification algorithm

Minimum age of $6 \mathrm{yr}$ for ADHD diagnosis

Including antibiotic exposure in hospitals

Restricting the cohort to first-born children

Including prenatal smoking, alcohol and drug exposure

Censoring at $12 \mathrm{yr}$

Censoring at $6 \mathrm{yr}$

\section{Negative-control analyses}

Maternal antibiotic exposure within $1 \mathrm{yr}$ before conception

Maternal antibiotic exposure within $1 \mathrm{yr}$ after childbirth
Hazard ratio $(95 \% \mathrm{Cl})$

$1.22(1.18-1.26)$

$1.23(1.19-1.28)$

$1.21(1.17-1.25)$

$1.24(1.20-1.28)$

$1.16(1.10-1.22)$

$1.20(1.15-1.25)$

$1.18(1.15-1.22)$

$1.08(1.04-1.11)$

$1.18(1.15-1.22)$

$1.23(1.19-1.27)$

Lower risk ; Higher risk

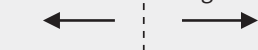

ind

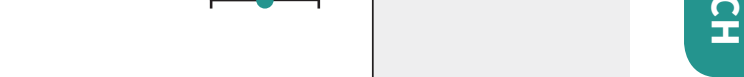


potential limitation. We addressed this issue by conducting a sensitivity analysis with a stricter identification algorithm and found no change in study results. Nondifferential misclassification of the clinical diagnosis of ADHD would have biased the results toward the null.

Misclassification of the exposure is another possibility, because exposure was defined on the basis of dispensation of medications, rather than actual use, and we could not account for nonadherence. The identification algorithm that we adopted defined medications for treating ADHD using the Anatomical Therapeutic Chemical code N06BA, which does not include the recently approved medication guanfacine. Therefore, some cases of ADHD could have been misclassified. The exposure definition also did not include in-hospital use. In a sensitivity analysis, we included the data available on in-hospital antibiotic dispensation, and the results remained unchanged.

Another potential limitation is unmeasured confounding by variables that were unavailable in the repository and are not shared by sibling pairs. Unmeasured confounding in the overall and matched cohorts may have overestimated the HRs. However, the sibling-controlled design likely avoided, to some extent, confounding by genetics and shared familial factors and is recommended for future studies examining the risk of ADHD.

Finally, the ADHD identification algorithm included only children with hyperactivity. Therefore, our findings may not be generalizable to children with the inattentive subtype of ADHD.

\section{Conclusion}

Prenatal antibiotic exposure was not associated with increased risk of ADHD. The association observed in some of the analyses was likely a result of confounding, as suggested by findings from the negative-control analyses and analyses of the sibling cohort. A discordant-sibling design is recommended for future studies.

\section{References}

1. Erskine HE, Ferrari AJ, Polanczyk GV, et al. The global burden of conduct disorder and attention-deficit/hyperactivity disorder in 2010. J Child Psychol Psychiatry 2014;55:328-36

2. What is ADHD? Atlanta: Centers for Disease Control and Prevention; 2017, reviewed 2019 Aug. 26. Available: www.cdc.gov/ncbddd/adhd/facts.html (accessed 2018 July 12).

3. Langlois KA, Samokhvalov AV, Rehm J, et al. Section C. Childhood conditions. In: Health state descriptions for Canadians. Ottawa: Statistics Canada; modified 2015 Nov. 27. Available: www.statcan.gc.ca/pub/82-619-m/2012004/sections/sectionc -eng.htm (accessed 2018 May 19).

4. Jaber L, Kirsh D, Diamond G, et al. Long-term functional outcomes in Israeli adults diagnosed in childhood with attention deficit hyperactivity disorder. Isr Med Assoc J 2015; 17:481-5.

5. Vingilis E, Erickson PG, Toplak ME, et al. Attention deficit hyperactivity disorder symptoms, comorbidities, substance use, and social outcomes among men and women in a Canadian sample. BioMed Res Int 2015;2015:982072.

6. Kirino E, Imagawa H, Goto T, et al. Sociodemographics, comorbidities, healthcare utilization and work productivity in Japanese patients with adult ADHD. PLoS One 2015;10:e0132233.

7. Polanczyk G, de Lima MS, Horta BL, et al. The worldwide prevalence of ADHD: a systematic review and metaregression analysis. Am J Psychiatry 2007;164:942-8.

8. Willcutt EG. The prevalence of DSM-IV attention-deficit/hyperactivity disorder: a meta-analytic review. Neurotherapeutics 2012;9:490-9.

9. Chartier M, Brownell M, MacWilliam L, et al. The mental health of Manitoba's children. Winnipeg: University of Manitoba, Rady Faculty of Health Sciences, Max Rady College of Medicine, Manitoba Centre for Health Policy; 2016.
10. Faraone SV, Larsson H. Genetics of attention deficit hyperactivity disorder. Mol Psychiatry 2019;24:562-75.

11. Akutagava-Martins GC, Rohde LA, Hutz MH. Genetics of attention-deficit/ hyperactivity disorder: an update. Expert Rev Neurother 2016;16:145-56.

12. Chang Z, Lichtenstein P, D'Onofrio BM, et al. Maternal age at childbirth and risk for ADHD in offspring: a population-based cohort study. Int J Epidemiol 2014;43:1815-24.

13. Sagiv SK, Epstein JN, Bellinger DC, et al. Pre-and postnatal risk factors for ADHD in a nonclinical pediatric population. J Atten Disord 2013;17:47-57.

14. van Dyk L, Springer P, Kidd M, et al. Familial-environmental risk factors in South African children with attention-deficit hyperactivity disorder (ADHD): a case-control study. J Child Neurol 2015;30:1327-32.

15. Motlagh MG, Katsovich L, Thompson N, et al. Severe psychosocial stress and heavy cigarette smoking during pregnancy: an examination of the pre- and perinatal risk factors associated with ADHD and Tourette syndrome. Eur Child Adolesc Psychiatry 2010;19:755-64.

16. Clements CC, Castro VM, Blumenthal SR, et al. Prenatal antidepressant exposure is associated with risk for attention-deficit hyperactivity disorder but not autism spectrum disorder in a large health system. Mol Psychiatry 2015;20:727-34.

17. Aarts E, Ederveen THA, Naaijen J, et al. Gut microbiome in ADHD and its relation to neural reward anticipation. PLoS One 2017;12:e0183509.

18. Jiang HY, Zhou YY, Zhou GL, et al. Gut microbiota profiles in treatment-naïve children with attention deficit hyperactivity disorder. Behav Brain Res 2018;347:408-13.

19. Borre YE, O'Keeffe GW, Clarke G, et al. Microbiota and neurodevelopmental windows: implications for brain disorders. Trends Mol Med 2014;20:509-18.

20. Petra Al, Panagiotidou S, Hatziagelaki E, et al. Gut-microbiota-brain axis and its effect on neuropsychiatric disorders with suspected immune dysregulation. Clin Ther 2015;37:984-95.

21. Warner BB. The contribution of the gut microbiome to neurodevelopment and neuropsychiatric disorders. Pediatr Res 2019;85:216-24.

22. Cenit MC, Nuevo IC, Codoñer-Franch P, et al. Gut microbiota and attention deficit hyperactivity disorder: new perspectives for a challenging condition. Eur Child Adolesc Psychiatry 2017;26:1081-92.

23. Tognini P. Gut microbiota: a potential regulator of neurodevelopment. Front Cell Neurosci 2017;11:25

24. Tochitani S, Ikeno $\mathrm{T}$, Ito $\mathrm{T}$, et al. Administration of non-absorbable antibiotics to pregnant mice to perturb the maternal gut microbiota is associated with alterations in offspring behavior. PLoS One 2016;11:e0138293.

25. Martin CR, Osadchiy V, Kalani A, et al. The brain-gut-microbiome axis. Cell Mol Gastroenterol Hepatol 2018;6:133-48.

26. Bonaz B, Bazin T, Pellissier S. The vagus nerve at the interface of the microbiota-gut-brain axis. Front Neurosci 2018;12:49.

27. Forsythe P, Bienenstock J. Immunomodulation by commensal and probiotic bacteria. Immunol Invest 2010;39:429-48.

28. Aagaard K, Ma J, Antony KM, et al. The placenta harbors a unique microbiome. Sci Transl Med 2014;6:237ra65.

29. Jiménez E, Fernández L, Marín ML, et al. Isolation of commensal bacteria from umbilical cord blood of healthy neonates born by cesarean section. Curr Microbiol 2005;51:270-4.

30. Tormo-Badia N, Håkansson $\AA$, Vasudevan K, et al. Antibiotic treatment of pregnant non-obese diabetic mice leads to altered gut microbiota and intestinal immunological changes in the offspring. Scand J Immunol 2014;80:250-60.

31. Schulfer AF, Battaglia T, Alvarez Y, et al. Intergenerational transfer of antibioticperturbed microbiota enhances colitis in susceptible mice. Nat Microbiol 2018; 3:234-42.

32. Subcommittee on Attention-Deficit/Hyperactivity Disorder; Steering Committee on Quality Improvement and Management; Wolraich M, Brown L, Brown RT, et al. ADHD: clinical practice guideline for the diagnosis, evaluation, and treatment of attention-deficit/hyperactivity disorder in children and adolescents. Pediatrics 2011;128:1007-22.

33. Schneeweiss S, Rassen JA, Glynn RJ, et al. High-dimensional propensity score adjustment in studies of treatment effects using health care claims data [published erratum in Epidemiology 2018;29:e63-4]. Epidemiology 2009;20:512-22.

34. Guertin JR, Rahme E, LeLorier J. Performance of the high-dimensional propensity score in adjusting for unmeasured confounders. Eur J Clin Pharmacol 2016;72:1497-505. 
35. Brownell M, De Coster C, Penfold R, et al. Manitoba child health atlas update. Winnipeg: University of Manitoba, Faculty of Medicine, Department of Community Health Sciences, Manitoba Centre for Health Policy; 2008.

36. Yallop L, Brownell M, Chateau D, et al. Lifetime prevalence of attention-deficit hyperactivity disorder in young adults: examining variations in the socioeconomic gradient. Can J Psychiatry 2015;60:432-40.

37. Brownell M, Chartier M, Santos R, et al. How are Manitoba's children doing? 2nd ed. Winnipeg: University of Manitoba, Faculty of Medicine, Department of Community Health Sciences, Manitoba Centre for Health Policy; 2012.

38. Brownell M, Chartier M, Au W, et al. The educational outcomes of children in care in Manitoba. Winnipeg: University of Manitoba, Faculty of Medicine, College of Medicine, Manitoba Centre for Health Policy; 2015.
39. Marín AM, Seco FL, Serrano SM, et al. Do firstborn children have an increased risk of ADHD? J Atten Disord 2014;18:594-7.

40. Mick E, Biederman J, Faraone SV. Is season of birth a risk factor for attentiondeficit hyperactivity disorder? J Am Acad Child Adolesc Psychiatry 1996;35: 1470-6.

41. Chateau D, Metge $\mathrm{C}$, Prior $\mathrm{H}$, et al. Learning from the census: the Socio-Economic Factor Index (SEFI) and health outcomes in Manitoba. Can J Public Health 2012;103(Suppl 2):S23-7. In French with English abstract.

42. Thompson JM, Waldie KE, Wall CR, et al. Associations between acetaminophen use during pregnancy and ADHD symptoms measured at ages 7 and 11 years. PLoS One 2014;9:e108210.
Competing interests: Salaheddin Mahmud has received unrestricted research grants from Merck, GlaxoSmithKline, Sanofi Pasteur, Pfizer and Roche-Assurex for unrelated studies, and has also received fees as an advisory board member for Sanofi Pasteur. Silvia Alessi-Severini has received unrestricted research grants from Merck and Pfizer for unrelated studies. No other competing interests were declared.

This article has been peer reviewed.

Affiliations: College of Pharmacy (Hamad, Alessi-Severini, Mahmud, Kuo), Manitoba Centre for Health Policy, Department of Community Health Sciences, Max Rady College of Medicine (Alessi-Severini, Brownell), and Department of Community Health Sciences, Max Rady College of Medicine (Mahmud, Brownell), Rady Faculty of Health Sciences, University of Manitoba, Winnipeg, Man.

Contributors: All authors contributed to the study concept and design and to data interpretation. Amani Hamad conducted data formatting and analysis. Amani Hamad and I fan Kuo contributed to data acquisition and drafted the manuscript. All authors revised the manuscript for important intellectual content, approved the final version for publication and agreed to act as guarantors of the work. Amani Hamad and I fan Kuo take full responsibility for the integrity of the data and accuracy of the analysis.

Funding: This work was supported by the University of Manitoba and the Evelyn Shapiro Award for Health Services Research. Salaheddin Mahmud's work is supported, in part, by funding from the Canada Research Chair Program.

Data sharing: We used de-identified data from the Manitoba Population Research Data Repository. The data are not publicly available but may be obtained from the data custodian, the Manitoba Centre for Health Policy (MCHP) at the University of Manitoba. Accessing the data requires submitting a formal request to MCHP and obtaining approvals from the Manitoba Health Information Privacy Committee and the Health Research Ethics Board of the University of Manitoba.

Acknowledgements: The authors thank Charles Burchill, Matt Dahl and Heather Prior, Manitoba Centre for Health Policy, for their valuable support. The authors also acknowledge the Manitoba Centre for Health Policy for allowing use of data contained in the Manitoba Population Research Data Repository under project no. H2016:244 (HIPC No. 2016/2017-11). The authors also thank Manitoba Health, Seniors and Active Living, the Winnipeg Regional Health Authority, the Manitoba Department of Families and Healthy Child Manitoba for contributing the data used in this study.

Disclaimer: The results and conclusions are those of the authors, and no official endorsement by the Manitoba Centre for Health Policy, Manitoba Health, Seniors and Active Living or other data providers is intended or should be inferred. Data used in this study are from the Manitoba Population Research Data Repository, housed at the Manitoba Centre for Health Policy, University of Manitoba, and were derived from data provided by Manitoba Health, Seniors and Active Living, the Winnipeg Regional Health Authority, the Manitoba Department of Families and Healthy Child Manitoba.

Accepted: Mar. 16, 2020

Correspondence to: I fan Kuo, I.Kuo@ umanitoba.ca 